\title{
Avoiding drunk driving with a push
}

\author{
Laila Marianne Martinussen ${ }^{1 *}$ (i) and Mikael Julius Sømhovd ${ }^{2}$
}

\begin{abstract}
The present study explores a novel approach for changing implicit attitudes toward drunk driving with behavioural training. Contrary to explicit attitudes, which people are consciously aware of and therefore can state, implicit attitudes are not necessarily consciously accessible; however, implicit attitudes also direct and affect behaviour. In order to combat problem behaviour such as drunk driving, it is, therefore, crucial to measure and target both types of attitudes. This randomised controlled study first measured implicit drunk driving attitudes. One week later, participants performed a behavioural training procedure, designed to influence implicit drunk driving attitudes, and a subsequent implicit drunk driving attitude test. We randomised young male participants into an experimental group that learned to avoid drunk driving stimuli and a control group performing a neutral version of the training setup. Results showed that behavioural training could change implicit drunk driving attitudes. However, contrary to expectations, the control group's implicit attitudes also changed. We propose that drivers can hold both positive and negative drunk driving implicit attitudes, and a priming effect may have contributed to the results. We outline and discuss the results.
\end{abstract}

Keywords: Implicit attitude change, Implicit and explicit attitudes, Drunk driving, GNAT, AAT, Traffic safety

\section{Introduction}

In road safety, one of the most salient problems is drunk driving. Drunk driving causes about $20 \%$ of all accidents in the Western world, and it can be up to $69 \%$ in low-income countries [1]. When drivers are asked to express their attitude toward drunk driving, they are overwhelmingly negative [2]. Thus, it seems that there is a mismatch between drunk driving attitudes and drunk driving behaviour. This mismatch might be because only explicit attitudes, i.e., what people explicitly say they believe, are measured; however, explicit drunk driving attitudes may not necessarily reflect drunk driving behaviour.

Because drunk driving is a socially stigmatised behaviour [3], it is likely that drivers are unwilling to express their real attitudes. The true explicit attitudes toward drunk driving may indeed be negative, but implicit attitudes may drive drunk driving behaviour to a greater extent than explicit ones. Consequently, interventions based only on explicit attitudes might not target the attitude that directs the problem behaviour and, hence, the effect of the attitude intervention will be limited (e.g. $[4,5])$. Therefore,

\footnotetext{
* Correspondence: laima@dtu.dk

'Department of Management Engineering, Technical University of Denmark, Diplomvej, Building 372, 2800 Kgs. Lyngby, Denmark

Full list of author information is available at the end of the article
}

to get a more detailed understanding of the psychological processes behind problem behaviour in traffic, it is essential to look into both explicit attitudes (i.e. how drivers' conscious attitudes influence behaviour) and implicit attitudes (i.e. how drivers' unconscious attitudes influence behaviour) [4, 6]. Measurement of implicit drunk driving attitudes and testing complementary intervention methods also targeting implicit attitudes are thus crucial in road safety research.

Unconscious processes can direct behaviour without a person's conscious awareness $[7,8]$. One way of tapping into these unconscious processes is measuring implicit attitudes. Contrary to explicit attitudes, which are introspectively accessible to the individual, implicit attitudes are 'introspectively unidentified (or inaccurately identified) traces of experience' ([9], p. 4).

Previous research has shown that implicit attitudes predicted spontaneous and stigmatised behaviour better than explicit attitudes, whereas explicit attitudes predict planned and deliberate behaviour better than implicit attitudes $[10,11]$. Thus, when trying to combat problem behaviour, it is crucial to know which of the attitudes motivates the behaviour, i.e., if the behaviour is unplanned and a result of spontaneous, automatic activation of memory patterns or is deliberate and planned 
[9]. As implicit attitudes are not necessarily assessable through conscious inspection, we measured them with a Go/No-go Association Task (GNAT), which is a computer-based reaction time test. In the GNAT, participants associate groups of target attitude object, for instance, picture stimuli of drunk driving, with attribute stimuli, for example, good or bad words. Signal detection analysis estimates a coefficient of 'sensitivity' to the associations and is thought to provide insight into the participant's memory patterns and unconscious preferences (see [12] for detailed information). The association between drunk driving stimuli and bad words is usually higher than to drunk driving stimuli, and good words as the former is a more readily conceived association. The difference between drunk driving stimuli combined with good words and drunk driving stimuli combined with bad words suggests an implicit attitude toward drunk driving. Because implicit attitudes may be a useful measure of attitudes towards socially unacceptable behaviours like drunk driving that also may direct behaviour, it is important to develop measures and procedures to facilitate change in implicit attitudes.

There are different ways to influence and change the two types of attitudes. Conscious reflection and consideration influence explicit attitudes, while straightforward behavioural training may influence implicit attitudes. For example, a method known as the Approach/Avoidance Task (AAT) can influence implicit attitudes. To mask the real intention with the method participants are instructed to either pull the joystick towards themselves or push it away dependent on whether the picture presents in landscape or portrait formats. In reality, the algorithm is that the majority of pictures that are pushed away is drunk driving related. Participants push a joystick away (avoidance behaviour), or pulls it toward themselves (approach behaviour), whenever a specific attitude object is shown [13-17]. Approaching attitude objects by pulling a joystick toward oneself may influence the implicit evaluation of the attitude objects positively. Conversely, avoidance behaviours such as pushing a joystick away when shown the same attitude objects may influence the evaluation negatively [14-22]. Such 'pro/ counter-attitudinal movements' have shown to change implicit attitudes toward various concepts such as math, race prejudice and alcohol consumption [14-17]. For example, Kawakami et al. [15] found that participants pulling a joystick toward themselves decreased prejudice as measured with an implicit attitude test, bolstering interpersonal behaviour observation included in the experiment.

To our knowledge, this is the first study in the field that aims to 1) explore drivers' implicit drunk driving attitudes and 2) to test whether the application of the AAT can influence those attitudes, thus broadening the current understanding of the inconsistency between drunk driving attitudes and drunk driving behaviour.
The study design is experimental, with young males randomised into an experimental or control group. We pre-tested implicit drunk driving attitudes with the GNAT [12], altered implicit drunk driving attitudes with the Approach-Avoidance Task (push/pull pictures with the joystick) in the experimental group, and used the GNAT to post-test attitudes. The control group performed a neutral version of the AAT, moving the joystick from side to side. We choose young male participants, as they are overrepresented in accidents statistics [23-26]. We hypothesize that the AAT can alter implicit drunk driving attitudes in similar ways as shown in previous AAT studies (e.g., [14-17]).

\section{Materials and method}

\subsection{Participants and procedure}

The participants were 57 male students between 18 and 31 (mean age 22.6) years old holding a drivers licence for a private car that we recruited on campus, or via a university Facebook page. We performed no formal power analysis, but the sample size is comparable with other relevant studies of the same methodological concepts (e.g., [15] = 44; [12] = 11; [17] = 42), In addition, since it is a clean experimental within-subject design (pre, - vs post-test implicit attitudes), not many participants was needed [27]. Participants completed the online pre-test GNAT to measure implicit attitudes toward drunk driving. One week later, they performed the AAT and the GNAT post-test in the lab. The study did not need an ethics statement, because according to the Danish law no ethical statement is needed for studies that do not use physiological measures, or invasive methods, which this study did not use. Participants were briefed and informed that they were free to leave at any time if they want to terminate their participation and they consented orally to participate. The data are anonymous and treated confidentially. We rewarded the participation with a gift card for brunch for two people.

\subsection{The go/no-go association task}

In the middle of the computer screen, our Go/No-go Association Task (GNAT) program presented either a picture or a word. Pictures were categorised as either showing a 'Dangerous' or a 'Not dangerous' traffic situation, or as neutral or not related to traffic. Pictures in the 'Dangerous' category were of situations particularly intended to elicit associations to drunk driving. Words were categorised as having either a 'Good' (e.g. beautiful) or a 'Bad' (e.g. vomit) meaning to it. The neutral traffic pictures were just fillers included to mask the purpose of the study and were not included in the analysis (for more information see [12]). Figure 1 describes the principles of the GNAT. 


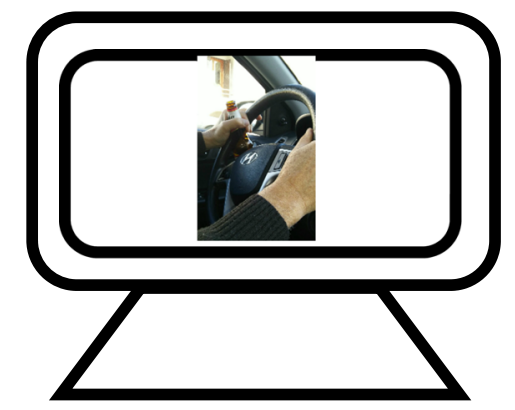

OR

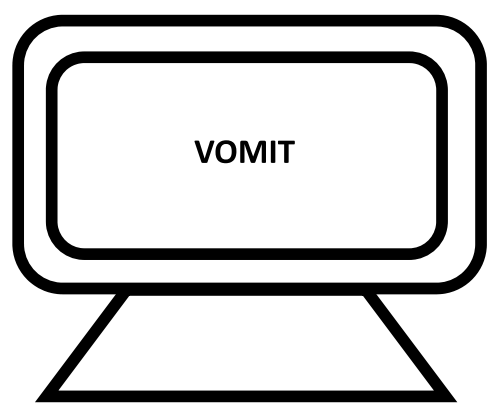

Fig. 1 Illustration of the GNAT method

For each of two experimental reaction time thresholds (750 and 600 milliseconds), a picture or a word were presented in random order in four blocks of 74 trials. The four $750 \mathrm{~ms}$ blocks ran before the four $600 \mathrm{~ms}$ blocks, but the order of the blocks was random within each threshold. This procedural variation ensures good reliability and is a particularly conservative strategy [12].

Between every block there were interleaved four different instruction pages that prompted a 'Go' response (pressing the spacebar) if the participant perceived the picture and word stimuli respectively as a) 'Dangerous' or 'Good', b) 'Dangerous' or 'Bad', c) 'Not dangerous' or 'Good, d) 'Not dangerous' or 'Bad'.

If the stimuli were not of the instructed attribute or value, no response ('No-go') should be given during the respective block. The participant manually started every block run from the respective instruction page. After a block had started, it ran without a break, until the next instruction page.

Performance on the GNAT is defined within a signal detection framework as the d-prime coefficient calculated from the pooled hit and miss ratio for the two thresholds. The d-prime indicates the sensitivity toward the respective combinations of pictures and words. For example, if the participant performs better, with more hits and fewer misses, to the combination of 'Dangerous' and 'Bad', it suggests that it is less conflicting to assess drunk driving pictures with the bad attribute simultaneously.

The participant is prompted to press the spacebar (GO response) if the stimuli appearing on the screen is a

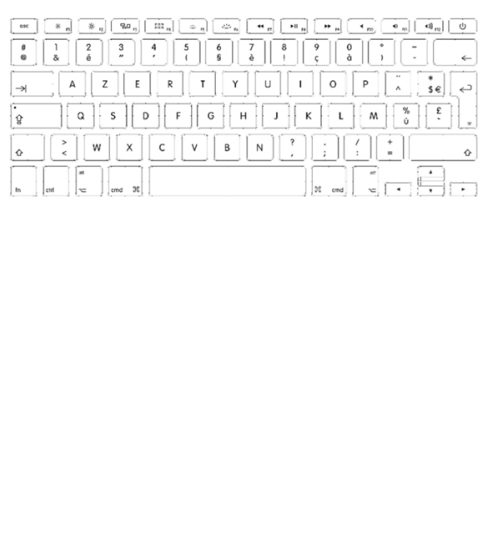

word with a BAD connotation to it or a picture that they associate with DANGEROUS, both the situations above should correctly elicit a space bar press (a HIT).

Failing to respond would be a MISS. Pressing the space bar when e.g. a neutral, not drunk driving related picture, or a GOOD word is presented would represent a FALSE alarm, and not pressing the space bar in such a situation would be a CORRECT rejection. All permutation are presented in separate blocks with its own instructions: GOOD/ NOT-DANGEROUS, GOOD/DANGEROUS, BAD/NOTDANGEROUS, BAD/DANGEROUS.

DANGEROUS is represented by drunk driving related pictures. NOT-DANGEROUS is represented with neutral pictures. Neutral pictures are only filler stimuli that is not used in analyses. All combinations are presented in separate blocks with both $750 \mathrm{~ms}$ and $600 \mathrm{~ms}$ thresholds. Sensitivity, D-prime, is calculated from the pooled HIT/MISS ratio from the two thresholds from the combinations GOOD/ DANGEROUS vs. BAD/DANGEROUS, respectively.

\subsection{The approach/avoidance task}

The Approach/Avoidance Task (AAT) is a method previously shown to change implicit attitudes [14-17]. The AAT works by pushing or pulling a joystick following instructions regarding stimuli shown on a computer screen. A joystick push represents avoidance behaviour whereas a pull represents an approach to behaviour. See Fig. 2 for an overview of the AAT setup.

In our study, participants in the experimental group were instructed to push the joystick when a picture in 


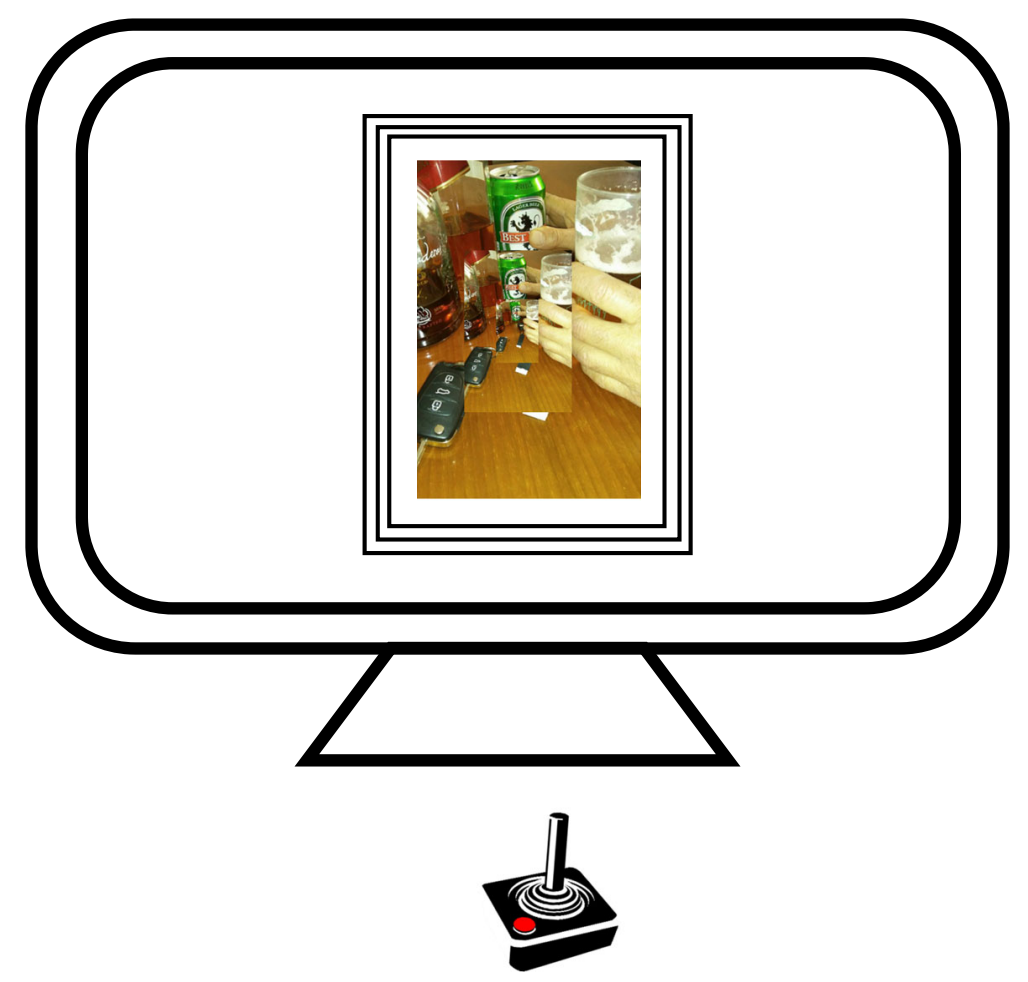

Fig. 2 Illustration of the AAT

landscape respectively portrait format appeared on the screen. The format was counterbalanced. The program then presented both drunk-driving related, neutral traffic-related pictures, and filler pictures with other content to mask the purpose. The drunk-driving related and the neutral traffic pictures were identical to the pictures used in the GNAT.

Unknowingly to the participants, and in addition to the format masking, $90 \%$ of the traffic pictures that appeared in which they were instructed to push the joystick away (avoid movement) were drunk driving-related pictures interleaved with $10 \%$ neutral traffic pictures and non-traffic related pictures. The intention is to strengthen the participant's propensity to avoid drunk-driving related stimuli.

In the control condition, the instructions were to move the joystick to the left or the right depending on picture format; that is, neither approach nor avoidance movements. Immediately following the AAT task, the participants completed a post-test GNAT measure identical to the pre-test GNAT.

The participant is prompted to push or pull the joystick if the picture appearing on the screen is in a randomly instructed format: landscape or portrait. As $90 \%$ of the pictures in the respective 'push-format' is, unknowingly to the participant, drunk driving related, the bulk of pictures pushed away is drunk driving related. Ten per cent of pictures interleaved is neutral to drinking and driving to mask the relation between the joystick direction and the picture content. Conversely, the 'pull-format' sequence contains $90 \%$ neutral pictures and 10\% drunk driving related pictures. Pictures in the 'push-format' diminishes in size on the screen until it disappears after pushing $1000 \mathrm{~ms}$. Pictures in the 'pull-format' increase in size.

\subsection{Analysis}

To account for the repeated measures in a common model with the experimental conditions, we ran a mixed one/way ANOVA, within the GLM suite of SPSS 24. As the hypothesis was that the AAT procedure would change the implicit evaluation of drunk driving, we modelled the experimental condition as a between subjects (BS) factor and the repeated pre-post measures as a within-subjects (WS) factor. The model also includes tests for interaction between the BS and WS factors.

We submitted separate sensitivity indices derived from the GNAT-blocks that included drunk driving pictures (i.e., the combinations drunk driving - Good and drunk driving - Bad).

GNAT performance was analysed within a signal detection framework, based on recommendations from the literature (e.g. [12-15]), using d prime as the estimate of sensitivity.

\section{Results}

Of 57 participants, 30 were in the Avoid condition. As Table 1 shows, all the means increased from pre- to post 
Table 1 Pre-test end post-test descriptive statistics of the D-prime score for the stimulus combinations

\begin{tabular}{|c|c|c|c|c|}
\hline & Group & Mean & Std. deviation & N \\
\hline \multirow[t]{2}{*}{ Pre-test drunk driving pictures and bad words } & Avoid & 1.09 & .56 & 30 \\
\hline & Control & 1.07 & .50 & 27 \\
\hline \multirow[t]{2}{*}{ Post-test drunk driving pictures and bad words } & Avoid & 1.30 & .43 & 30 \\
\hline & Control & 1.35 & .53 & 27 \\
\hline \multirow[t]{2}{*}{ Pre-test drunk driving pictures and good words } & Avoid & .58 & .54 & 30 \\
\hline & Control & .57 & .53 & 27 \\
\hline \multirow[t]{2}{*}{ Post-test drunk driving pictures and good words } & Avoid & .75 & .58 & 30 \\
\hline & Control & .65 & .49 & 27 \\
\hline
\end{tabular}

measures. This main effect was statistically significant $(\mathrm{F}=16.7, p<.001)$ and explained $\sim 23 \%$ of the variance in the model. Mauchly's test and Levene's test suggested no violation of sphericity or error variance assumptions.

Furthermore, as can be seen in Table 2, both the avoid group and the control group saw a significant increase in their sensitivity to this combination of drunk driving and bad words with a corrected significance of $(p=.13$ and $p=.002$, respectively). This means that the control group also significantly increased their post-test performance on the evaluation representing a preferable (negative) implicit attitude toward drunk driving. Figure 3 demonstrates that the change is comparable and the random variance and interaction is negligible.

As for the drunk driving and good stimulus pairs (which is the less preferred combination to be sensitive to) all means do indeed increase from pre-test to post-test (see Table 3). However, for this combination, the increase is only statistically significant for the avoid group. This is illustrated in Fig. 4 with the noticeably steeper pre-post slope in the Avoid group. The interaction effect between the groups is not significant in any of the groups.

\section{Discussion}

Participants in both the experimental (pushing away the joystick) and the control condition (sideways movements) in the AAT, significantly increased their sensitivity to the association between drunk driving related picture stimuli and negative word stimuli. Sensitivity to the association between drunk driving pictures and positive words also significantly increased, but only for participants in the experimental condition. Before the procedure, the participants in both conditions were significantly more sensitive to the association of drunk driving pictures with bad words compared to drunk driving and good words.

The fact that both experimental and control condition increased the sensitivity to drunk driving pictures and good words may suggest that the method of implicit learning worked, but that the control condition had flaws. The increase in sensitivity of the drunk driving and good words association in the experimental condition may express that the method worked primarily as a primer leading to a general increase of sensitivity. As this study is exploratory of this novel approach to influencing of automatic attitudes towards drunk driving, we will delineate the possible explanations, and propose possible amendments for further research.

First, the fact that the side-to-side joystick movements also increased sensitivity to the drunk driving pictures paired with bad words may indicate a detectable positive learning or priming effects [28] emerging regardless of the direction of the joystick movement. Physiologically however, the difference between pushing the joystick and the side-to-side movements are minute. For instance, for a right-handed participant a left movement would primarily activate flexor muscles in about the same way as would a pull at the joystick and proprioceptive have be perceived as pulling. Conversely, a right movement utilise extensor muscles, and may mimic the push in the experimental conditions we did not differentiate between left and right directions in the collected data. However, this common method variability is a matter of speculation at this point. Possible amendments to the control condition to delineate this in further

Table 2 Sensitivity change to the drunk driving pictures and bad words from the experimental conditions

\begin{tabular}{lcccccccc}
\hline Group & Pre-test & Post-test & Mean difference & Std. error & Sig. & & \multicolumn{2}{c}{$95 \%$ C. I. } \\
\cline { 3 - 8 } & & & & & & Lower bound & Upper bound \\
\hline Avoid & 1 & 2 & $-.211^{a}$ & .082 & .013 & -.375 & -.047 \\
Control & 1 & 2 & $-.275^{a}$ & .086 & .002 & -.447 & -.102 \\
\hline
\end{tabular}

${ }^{a}$ The mean difference is significant at the .05 level 


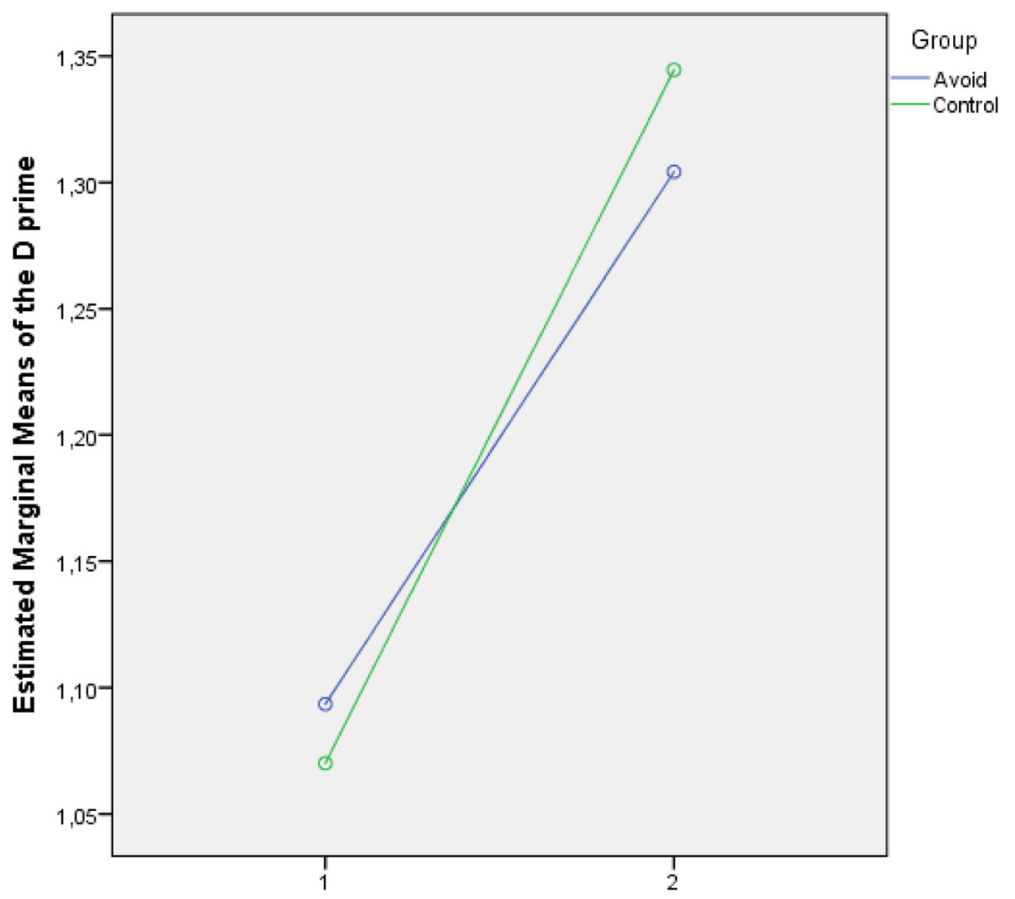

Fig. 3 Estimated marginal means by time for the drunk driving and bad words combination for the experimental conditions

research is proposed in 'Limitations and Implications for Future Research' below.

Secondly, the experimental condition increased sensitivity to both the drunk driving is bad association and the drunk driving is good association. This may indeed be a result of a stronger general learning effect in the experimental conditions the drunk driving is good association is weaker initially. Pushing the joystick increase sensitivity to both positive and negative association to drunk driving may also have to do with how the movement is perceived. The push, meant to represent avoiding, might just as well be perceived as reaching for it.

Thirdly, people may simultaneously hold both positive and negative attitudes toward the same attitude object (e.g., $[29,30])$. Like sweets are both fattening and good to eat, smoking is both pleasurable and dangerous, drunk driving may be pleasurable or accepted but is also dangerous. In Denmark it is allowed to drive with up to 0.5 per mille blood-alcohol concentration, meaning that it is (depending on factors as metabolism and weight) legal to drive after consuming about one to two units of alcohol. As drinking is generally perceived as positive, and may be ensued by a perfectly legal and acceptable drive home may introduce a dual, or graded, attitude pattern towards drunk driving ('It is okay to drink a bit and then drive), but not to drink a lot and then drive. Such an interpretation is bolstered by studies of implicit evaluations and the dual nature of alcohol-related attitudes $[29,30]$. Wiers and colleagues [29, 30] showed that the participants held both arousing and calming associations to alcohol. Relating to our study, it seems that depending on the amount of alcohol suggested to be involved participants may hold both positive and negative implicit and explicit drunk driving attitudes.

\subsection{Limitations and implications for future research}

Our sample of only young male students restricts the generalizability of the results to other driver groups. This demographic, more than older driver groups, may have more ambivalent attitudes toward drunk driving because of, for example, greater willingness to take risks than other demographic groups. Future research should thus

Table 3 Sensitivity change to the drunk driving pictures and good words from the experimental conditions

\begin{tabular}{|c|c|c|c|c|c|c|c|}
\hline \multirow[t]{2}{*}{ Group } & \multirow[t]{2}{*}{ Pre-test } & \multirow[t]{2}{*}{ Post-test } & \multirow[t]{2}{*}{ Mean difference } & \multirow[t]{2}{*}{ Std. error } & \multirow[t]{2}{*}{ Sig. } & \multicolumn{2}{|l|}{$95 \%$ C. I } \\
\hline & & & & & & Lower bound & Upper bound \\
\hline Avoid & 1 & 2 & $-.175^{a}$ & .079 & .030 & -.333 & -.017 \\
\hline Control & 1 & 2 & -.084 & .083 & .317 & -.250 & .083 \\
\hline
\end{tabular}

The mean difference is significant at the .05 level 


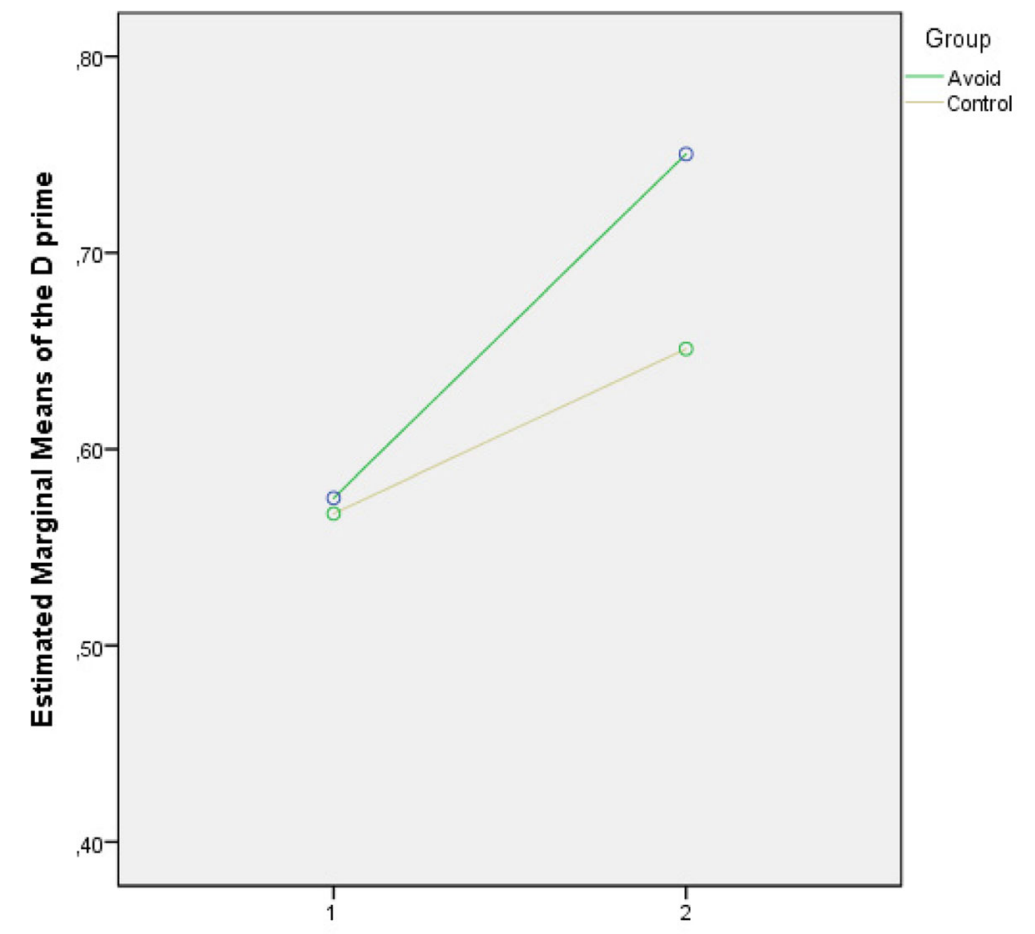

Fig. 4 Estimated marginal means by time for the drunk driving and good words combination for the experimental conditions

explore the change of implicit attitudes among other demographics, ideally also drunk driving offenders.

To delineate the priming and learning effects from the effect of the behavioural training, the complex sideways hand movements in the control condition should be replaced by a control condition wherein the participant passively views the AAT program running on the screen. Ideally, a third condition should be an 'approach' condition where the participant pulled the joystick towards her, but that would introduce unacceptable ethical issues if it actually increased the participants propensity for drunk driving.

Whether the forward motion of the joystick represents pushing away or stretching out may be disentangled by explicitly explaining the intended evaluation of the motion. A push movement may be validated by exclaiming a 'no', 'yes', or simply 'I want this' alongside the joystick movement. Multiple modes of behaviour like exclamations have proven effective in other research (e.g., [13]).

Finally, a mixed model, taking into consideration the random effects of priming, learning, and behavioural training may also answer some of these speculations, but require considerably higher statistical power. A larger sample would also allow for investigating potential subgroups interpreting the movements differently.

\section{Conclusion}

The AAT seems to make already negative attitudes towards drunk driving more negative. However, after this exploratory first attempt of applying implicit learning methods to attitudes of drunk driving, it is crucial that further studies investigate and delineate the magnitude of methods variance, priming effect, and confounding from general learning effect. The method has potential benefits for influencing implicit attitudes, which is thought to be crucial to predict behaviour in socially sensitive realms, but more robust methods for implicit attitude change should be explored by the inclusion of additional behavioural component in the learning procedure to strengthen and validate it. Replication of the findings among other samples than young male drivers, such as age, gender and educational level, and participants that have already been driving under the influence of alcohol or drugs would be of interest.

Acknowledgements

Thanks to Laura Petranca for help with the data collection and thanks to TrygFonden for financial support of the project.

\section{Funding}

TrygFonden funded the project.

\section{Availability of data and materials}

The datasets used and analysed during the current study are available from the corresponding author on reasoned request. 


\section{Authors' contributions}

LMM made the project description and was project leader on the project, also responsible for data collection and study design, and was a major contributor in writing the manuscript. MJS analysed the data and contributed to the writing of the manuscript. LMM and MJS interpreted the results. Both authors read and approved the final manuscript.

\section{Competing interests}

The authors declare that they have no competing interests.

\section{Publisher's Note}

Springer Nature remains neutral with regard to jurisdictional claims in published maps and institutional affiliations.

\section{Author details}

'Department of Management Engineering, Technical University of Denmark, Diplomvej, Building 372, 2800 Kgs. Lyngby, Denmark. ${ }^{2}$ Tyrilistiftelsen, Normannsgata 47, 0655 Oslo, Norway.

\section{Received: 13 October 2018 Accepted: 19 February 2019}

Published online: 04 March 2019

\section{References}

1. World Health Organization (WHO). Drinking and Driving - An International Good Practice Manual. Global Road Safety Partnership 2007; 2007 [cited 10 May 2018]. Available from: http://www.who.int/roadsafety/projects/manuals/ alcohol/en/.

2. SARTRE. (2004). 3 consortium. European drivers and road risk. Part 1. Report on principal analyses. Paris: INRETS.

3. Kraha, A. (2013). Assessing drinking and driving attitudes and behavior: Factor structure of the drinking and driving scale. New School Psychology Bulletin, 10, 52-57.

4. Hoekstra, T., \& Wegman, F. (2011). Improving the effectiveness of road safety campaigns: Current and new practices. IATSS Research, 34, 80-86.

5. Ulleberg, P., \& Rundmo, T. (2003). Personality, attitudes and risk perception as predictors of risky driving behaviour among young drivers. Safety Science, $41,427-443$.

6. Sibley, C. G. Harré, N. (2009). A gender role socialization model of explicit and implicit biases in driving self-enhancement. Transportation Research Part F: Traffic Psychology and Behaviour, 12, 452-461.

7. Chen, M., \& Bargh, J. A. (1999). Consequences of automatic evaluation: Immediate behavioral predispositions to approach or avoid the stimulus. Personality and Social Psychology Bulletin, 25, 215-224.

8. Dovidio, J. F., Kawakami, K., Johnson, C., Johnson, B., \& Howard, A. (1997). On the nature of prejudice: Automatic and controlled processes. Journal of Experimental Social Psychology, 33, 510-540.

9. Greenwald, A. G. \& Banaji, M. R. (1995). Implicit social cognition: Attitudes, self-esteem, and stereotypes. Psychological Review, 102, 4-27.

10. Perugini, M. (2005). Predictive models of implicit and explicit attitudes. British Journal of Social Psychology, 44, 29-45.

11. Rydell, R. J., \& McConnell, A. R. (2006). Understanding implicit and explicit change: A system of reasoning analysis. Journal of Personality and Social Psychology Pharmacol Biochem Be, 91, 995-1008.

12. Nosek, B. A., \& Banaji, M. R. (2001). The go/no-go association task. Social Cognition, 19, 625-666

13. Kawakami, K., Dovidio, J. F., Moll, J., Hermsen, S., \& Russin, A. (2000). Just say no (to stereotyping): Effects of training in negation of stereotypic associations on stereotype activation. Journal of Personality and Social Psychology, 41, 871-888.

14. Kawakami, K., Dovidio, J. F., \& van Kamp, S. (2007). The impact of counterstereotypic training and related correction processes on the application of stereotypes. Group Process Intergroup Relat, 10, 141-158.

15. Kawakami, K., Phillis, C. E., Steele, J. R., \& Dovidio, J. F. (2007). Close distance makes the heart grow fonder: Improving implicit racial attitudes and interracial interactions through approach behaviors. Journal of Personality and Social Psychology, 6, 957-971

16. Wiers, R. W. Eberl, C, Rinck, M., Becker, E. S., \& Lindenmeyer, J. (2011). Retraining automatic action tendencies changes alcoholoic patients approach bias for alcohol and improves treatment outcome. Psychological Science, 22, 490-497.

17. Wiers, R. W., Rinck, M., Kordts, R., \& Houben, K. (2010). Starck F.Retraining automatic action-tendencies to approach alcohol in hazardous drinkers. Addiction, 105, 279-287.

18. Cacioppo, J. T., Priester, J. R., \& Berntson, G. G. (1993). Rudimentary determinants of attitudes: II. Arm flexion and extension have differential effects on attitudes. Journal of Personality and Social Psychology, 65, 5-17.

19. Förster, J., \& Strack, F. (1997). Motor actions in retrieval of valenced information: A motor congruence effect. Perceptual and Motor Skills, 85, 1419-1427.

20. Förster, J., \& Strack, F. (1997). Motor actions in retrieval of valenced information: II. Boundary conditions for motor congruence effects. Perceptual and Motor Skills, 86, 1423-1426.

21. Neumann, R., \& Strack, F. (2000). Approach and avoidance: The influence of proprioceptive and exteroceptive cues on encoding of affective information. Journal of Personality and Social Psychology, 79, 39-48.

22. Priester, J. R., Cacioppo, J. T., \& Petty, R. E. (1996). The influence of motor processes on attitudes toward novel versus familiar semantic stimuli. Personality and Social Psychology Bulletin, 22, 442-447.

23. European Transport Safety Council (ETSC). (2011). Road safety performance index. Flash 21. Reducing road deaths among young people aged 15-30. Brussels: ETSC.

24. Hansen, A. S., \& Jensen, C. (2012). Risiko i trafikken 2007-2010 [risk in traffic 2007-2010]. DTU transport. Report, 4.

25. OECD. (2006). Young drivers - The road to safety. Transport research Centre. ECMT. Paris: OECD Publishing.

26. Twisk, D., \& Stacey, C. (2007). Trends in young driver risk and countermeasures in European countries. Journal of Safety Research, 38, 245-257.

27. De Winter, J. C. F., \& Dodou, D. (2017). Human subject research for engineers. SpringerBriefs in Applied Sciences and Technology. https://doi.org/10.1007/ 978-3-319-56964-2_2

28. Dijksterhuis, A., \& Bargh, J. A. (2001). The perception-behavior expressway: Automatic effects of social perception on social behavior. Advances in Experimental Social Psychology, 33, 1-40.

29. Wiers, R. W., Van Woerden, N., Smulders, F. T. Y., \& De Jong, P. J. (2002). Implicit and explicit alcohol-related cognitions in heavy and light drinkers. Journal of Abnormal Psychology, 111, 648-658.

30. Wiers, R. W., Van de Luitgaarden, J., Van den Wildenberg, E., \& Smulders, F. T. Y. (2005). Challenging implicit and explicit alcohol-related cognitions in young heavy drinkers. Addiction, 100, 806-819.

\section{Submit your manuscript to a SpringerOpen ${ }^{\circ}$ journal and benefit from:}

- Convenient online submission

- Rigorous peer review

- Open access: articles freely available online

- High visibility within the field

- Retaining the copyright to your article

Submit your next manuscript at $\boldsymbol{\nabla}$ springeropen.com 